\title{
Biomassa, estoques de carbono e de nutrientes em estádios sucessionais da Floresta Atlântica, RJ
}

\author{
Anderson Ribeiro Diniz¹, Deivid Lopes Machado², Marcos Gervasio Pereira, \\ Fabiano de Carvalho Balieiro ${ }^{3}$, Carlos Eduardo Gabriel Menezes ${ }^{4}$
}

\footnotetext{
${ }^{1}$ Universidade Federal Rural do Rio de Janeiro, Instituto de Agronomia, Departamento de Solos, BR 465, CEP 23851-970, Seropédica-RJ, Brasil. E-mail: andersonribeiro02@gmail.com; mgervasiopereira01@gmail.com; carlos.menezes@ifrj.edu.br

${ }^{2}$ Universidade Estadual Paulista Júlio de Mesquita Filho, Faculdade de Ciências Agronômicas de Botucatu, Rua José Barbosa de Barros, 1780, Jardim Paraíso, CEP 18610-307, Botucatu-SP, Brasil. E-mail: deivid.machado@ig.com.br;

${ }^{3}$ Embrapa Solos, Rua Jardim Botânico, 1024, Jardim Botânico, CEP 22460-000, Rio de Janeiro-RJ, Brasil. E-mail: fabiano.balieiro@embrapa.br

${ }^{4}$ Instituto Federal de Educação, Ciência e Tecnologia do Rio de Janeiro, Campus Nilo Peçanha - Pinheiral, 550, Rua José Breves - Centro, CEP 27197-000, Pinheiral-RJ, Brasil. E-mail: carlos.menezes@ifrj.edu.br
}

\section{RESUMO}

Os fragmentos florestais inseridos no domínio da Floresta Atlântica apresentam grande importância em relação ao estoque de carbono e a ciclagem de nutrientes. Este estudo objetivou estimar a biomassa e o estoque de carbono na biomassa, 0 estoque de serapilheira e o estoque de carbono e nutrientes na serapilheira, em duas florestas estacionais semideciduais com diferentes estádios sucessionais ( 25 e 65 anos), classificadas como floresta secundária em estádio médio (FSEM) e floresta secundária em estádio avançado (FSEA), localizadas na Bacia do Rio Paraíba do Sul, Pinheiral, RJ. Em cada estádio sucessional foi delimitada uma parcela de $50 \times 50 \mathrm{~m}$, onde foram realizadas as amostragens. A biomassa estimada acima do solo foi de 44,3 $\mathrm{Mg} \mathrm{ha}^{-1}$ na FSEM e 131,6 Mg ha-1 na FSEA, sendo os valores totais, incluindo a biomassa de raízes, respectivamente de $57,6 \mathrm{Mg} \mathrm{ha}^{-1}$ e 171,0 Mg ha-1. O estoque de carbono da biomassa aérea foi 20,8 $\mathrm{Mg} \mathrm{ha}^{-1}$ na FSEM e 61,8 $\mathrm{Mg} \mathrm{ha}^{-1}$ na FSEA. Com relação à serapilheira, verificaram-se maiores valores do estoque, teores e conteúdos de carbono orgânico e nutrientes na FSEA. $A$ serapilheira acumulada no solo se mostrou como uma importante via de transferência de $\mathrm{N}$, Ca e Mg, destacando-se os teores e conteúdos de N na FSEA e de Ca na FSEM.

Palavras-chave: ciclagem de nutrientes, sequestro de carbono, serapilheira, sucessão florestal

\section{Biomass, carbon stocks and nutrients in successional stages of the Atlantic Forest, Rio de Janeiro, Brazil}

\begin{abstract}
The forest fragments inserted in the area of Atlantic Forest have great importance in relation to the stock of carbon and nutrient cycling.This study aimed to estimate the biomass and carbon stock in biomass, litter stocks and stocks of carbon and nutrients in litter fall in two forests, with different successional stages (25 and 65), classified as secondary forest in medium stage (SFMS) and secondary forest in an advanced stage (SFAS), located in the basin of the Paraíba do Sul River, Pinheiral, RJ. In each successional stage was enclosed a plot of $50 \times 50 \mathrm{~m}$, where the samples were performed. The estimated above-ground biomass was $44.3 \mathrm{Mg}$ $\mathrm{ha}^{-1}$ in FSEM and $131.6 \mathrm{Mg} \mathrm{ha}^{-1}$ in FSEA, with the totals, including root biomass, respectively $57.6 \mathrm{Mg} \mathrm{ha}^{-1}$ and $171.0 \mathrm{Mg}^{-1}$. The carbon stock of aboveground biomass was $20.8 \mathrm{Mg} \mathrm{ha}^{-1}$ in FSEM and $61.8 \mathrm{Mg} \mathrm{ha}^{-1}$ in FSEA. With regard to litter, there were higher values of inventory levels and contents of organic carbon and nutrients in FSEA. The accumulated litter on the ground proved to be an important transfer of $\mathrm{N}, \mathrm{Ca}$ and $\mathrm{Mg}$, standing out the contents of $\mathrm{N}$ on FSEA and the contents of $\mathrm{Ca}$ on FSEM.
\end{abstract}

Key words: nutrients ciclyng, carbon sequestration, litter, forest succession 


\section{Introdução}

As florestas tropicais são um dos maiores ecossistemas do planeta, ao mesmo tempo em que são fontes de matéria prima como a madeira e produtos utilizados na indústria farmacêutica, além de contribuir para a manutenção da vida no planeta por meio de serviços ecológicos como a regulação do clima, a ciclagem de nutrientes, a qualidade da água, beleza cênica e recreação (Henriques, 2010).

A cobertura florestal tropical cobre extensas áreas em todo o planeta (17 milhões de $\mathrm{km}^{2}$ ), correspondendo $20 \%$ da superfície terrestre (FAO, 2011). Assim, no contexto das mudanças climáticas globais, áreas florestais representam sumidouros de $\mathrm{C}$ e têm sua importância destacada graças à capacidade natural dos vegetais de sequestrar $\mathrm{CO}_{2}$ da atmosfera, por meio da fotossíntese, e fixá-lo sob a forma de carbono na biomassa lenhosa, folhas e raízes em seus compartimentos aéreos, subterrâneos, como também o solo (Cheng et al. 2007).

A capacidade produtiva das florestas é decorrente do conteúdo de nutrientes que são transferidos ao solo, sendo a deposição de serapilheira a principal via responsável pela entrada de nutrientes no sistema florestal. A entrada de nutrientes resultante do material orgânico aportado no solo condiciona alterações nas características físicas, químicas e biológicas do solo (Vitousek \& Sanford, 1986). Desta forma, informações sobre a ciclagem de nutrientes nas florestas tropicais geram informações sobre a dinâmica de ciclagem de nutrientes, e assim é possível inferir sobre os fluxos entre os diferentes compartimentos do material depositado no solo florestal (Viera et al., 2010).

Entretanto, ainda são escassas as estimativas de biomassa, e de estoques de carbono e de nutrientes para essas formações florestais, especialmente para a Floresta Atlântica. Adiversidade de formações vegetais da formação (Rizzini, 1979) associada à existência de fragmentos de diferentes tamanhos e formas (Ribeiro et al., 2009a) fazem dessas estimativas variadas e muitas vezes pouco precisas.

A região do médio vale Paraíba está inserida sob o domínio da Floresta Atlântica, numa paisagem caracterizada por mares de morros. Essa região foi muito desconfigurada com os ciclos econômicos de desenvolvimento do Brasil, em que grande parte das áreas florestais cedeu lugar às culturas de cana-deaçúcar e café. Hoje, extensas áreas dessa região se encontram predominantemente coberta por pastagens em algum estádio de degradação (SOS Mata Atlântica, 2011).

Nesse mosaico de usos, os fragmentos florestais secundários da região se tornam importantes componentes da paisagem, pois além de conservarem a biodiversidade remanescente, são agentes da regulação hídrica, podem estocar quantidades significativas de carbono, e serem provedores de outros serviços, interferindo assim positivamente na produção agropecuária local por meio da manutenção de polinizadores, inimigos naturais, dentre outros (Celentano et al., 2011).

Diante da escassez de informações sobre as florestas secundárias nessa região, este estudo tem como objetivo estimar a biomassa e o estoque de carbono da biomassa, o estoque de serapilheira e o estoque de carbono e nutrientes na serapilheira em dois estádios sucessionais da Floresta Atlântica na Bacia do Médio Vale Paraíba do Sul, em Pinheiral, RJ.

\section{Material e Métodos}

\section{Localização e caracterização das áreas de estudo}

$\mathrm{O}$ estudo foi realizado no município de Pinheiral, Rio de Janeiro, na região do Médio Paraíba Fluminense, situado na sub-bacia do Ribeirão Cachimbal, que compõe a bacia hidrográfica do rio Paraíba do Sul, localizado entre as latitudes $22^{\circ} 29^{\prime} 03^{\prime \prime}$ e $22^{\circ} 35^{\prime} 27^{\prime \prime} \mathrm{S}$ e entre as longitudes $43^{\circ} 54^{\prime} 49^{\prime \prime} \mathrm{W}$ e $44^{\circ} 04^{\prime} 05^{\prime \prime} \mathrm{W}$.

O clima da região, de acordo com a classificação de Köppen, foi classificado em Cwa - clima temperado de inverno seco e verão chuvoso e Am - clima tropical chuvoso com inverno seco. A região apresenta precipitação anual em torno de 1.300 mm e temperatura média anual de $21^{\circ} \mathrm{C}$.

A região está inserida no domínio ecológico da Floresta Atlântica, cuja vegetação original denomina-se Floresta Estacional Semidecidual Submontana, característica de zonas de altitudes entre 300 e $800 \mathrm{~m}$. A vegetação atualmente dominante na região é constituída por pastagens, implantadas e espontâneas não manejadas, que se apresentam em diferentes estádios de degradação, nível de uso e/ou abandono, dando origem às demais formas de vegetação da área, como os pastos sujos e as capoeiras em diferentes níveis sucessionais (Menezes, 2008).

$\mathrm{O}$ estudo foi realizado em um fragmento que possui área de 190 hectares. Os estádios sucessionais avaliados estão inseridos nesse fragmento e foram selecionados por Menezes (2008), estudando atributos do solo no Médio Vale do Paraíba do Sul, Pinheiral, RJ. O autor definiu as áreas com base na interpretação de fotografias aéreas e informações históricas de uso das terras, obtidas com antigos moradores do município de Pinheiral, RJ, que residiam e utilizavam as terras na sub-bacia em estudo, entre as décadas de 1950 e 2000. A partir dessas informações, o autor fez o reconhecimento do fragmento in loco buscando definir áreas com diferentes estádios sucessionais, mas com mesmas condições edafoclimáticas, como posicionamento na encosta (terço superior), face de exposição, declividade e classe de solo. Em função dessas características foi possível delimitar uma parcela de 50 × $50 \mathrm{~m}$, em cada estádio sucessional.

De acordo com a resolução (06/94) do CONAMA as áreas foram classificadas em dois estádios sucessionais da Floresta Atlântica, a saber: Floresta Secundária em Estádio Médio (FSEM) e Floresta Secundária em Estádio Avançado (FSEA) (Menezes, 2008). A seguir são apresentados o histórico e a caracterização dos estádios sucessionais.

- Floresta secundária em estádio médio de sucessão (FSEM): localiza-se no terço superior da encosta, a altitude de $466,7 \mathrm{~m}$. A área se encontrava até 1985 , sob cobertura de pasto sujo com formação inicial de capoeira, sendo também protegida por cerca, o que permitiu o desenvolvimento sucessional. Apresenta fisionomia arbustivo/arbórea, com início de estratificação e ocorrem espécies de sombra. 
Tabela 1. Atributos químicos e análise granulométrica na camada de $0-40 \mathrm{~cm}$, das florestas estacionais semideciduais em estádio médio (FSEM) e estádio avançado (FSEA), Pinheiral, RJ

\begin{tabular}{|c|c|c|c|c|c|c|c|c|c|c|c|c|c|c|}
\hline \multirow{2}{*}{ Área } & $\mathbf{p H}$ & $\mathbf{P}$ & $\mathbf{A l}^{3^{+}}$ & H & $\mathrm{Ca}^{2+}$ & $\mathrm{Mg}^{2+}$ & $\mathbf{N a}^{+}$ & $\mathbf{K}^{+}$ & Valor S & Valor $\mathbf{T}$ & \multirow{2}{*}{$\begin{array}{l}\mathrm{V} \\
\%\end{array}$} & Argila & Silte & Areia \\
\hline & $\mathrm{H}_{2} \mathrm{O}$ & $\mathrm{mg} \mathrm{dm}^{-3}$ & \multicolumn{8}{|c|}{$\mathrm{cmol}_{\mathrm{c}} \mathrm{kg}^{-1}$} & & \multicolumn{3}{|c|}{$\mathbf{g} \mathbf{k g}^{-1}$} \\
\hline FSEM & 5,0 & 0,3 & 1,64 & 2,98 & 1,06 & 1,42 & 0,05 & 0,23 & 2,75 & 7,38 & 35 & 328 & 223 & 450 \\
\hline FSEA & 4,3 & 0,6 & 2,08 & 2,91 & 0,84 & 0,98 & 0,02 & 0,12 & 1,95 & 6,94 & 28 & 318 & 223 & 460 \\
\hline
\end{tabular}

- Floresta secundária em estádio avançado de sucessão (FSEA): localiza-se a altitude de 521,9 m, em terço superior da encosta. Pelos relatos de moradores, essa área é considerada a mais antiga da porção inferior da sub-bacia, sendo a cobertura florestal formada após a decadência da cafeicultura na região. A área apresenta fisionomia arbórea, com árvores emergentes, subbosque já diferenciado, formado por espécies tolerantes, grande variedade de espécies lenhosas, grande número de indivíduos regenerantes e presença de lianas e epífitas em abundância.

Com relação ao tipo de solo, os diferentes estádios sucessionais se encontram sob Cambissolo Háplico Distrófico típico (Menezes, 2008), sendo apresentados na Tabela 1 os atributos químicos e análise granulométrica que foram realizadas no Laboratório de Gênese e Classificação dos Solos da UFRRJ, conforme (Embrapa, 1997).

\section{Levantamento florístico e fitossociológico}

Nas áreas de FSEA e FSEM foi utilizado o método do transecto (Sylvestre \& Rosa, 2002) para a realização do levantamento florístico. Foram marcados três transectos de $2 \times 50 \mathrm{~m}$, nos quais foram amostrados todos os indivíduos lenhosos com diâmetro a altura do peito (DAP) igual e superior a $2,5 \mathrm{~cm}$ que foram interceptados. Todos os indivíduos amostrados nestes transectos foram marcados com etiquetas de alumínio, tiveram mensurado o DAP, estimada a sua altura máxima a partir do solo, sendo o material botânico coletado com o auxílio de tesoura de poda alta. Os parâmetros fitossociológicos adotados foram: densidade absoluta (DA), densidade relativa (DR), frequência absoluta (FA), frequência relativa (FR), dominância (DO) e dominância relativa (DOR) que foram utilizados para a determinação do índice de valor de importância (IVI) das espécies.

\section{Biomassa e estoque de carbono}

A biomassa da comunidade vegetal acima do solo nos dois estádios de sucessão (FSEM e FSEA) foi determinada indiretamente utilizando-se o modelo alométrico (Equação 1), ajustado por Scolforo et al. (2008) para floresta estacional semidecidual:

$$
\begin{aligned}
\operatorname{Ln}(\mathrm{PS}) & =-10,439791707+2,1182873001 \cdot \operatorname{Ln}(\text { Dap })+ \\
& +\quad 0,8339834928 \cdot \operatorname{Ln}(\mathrm{H})
\end{aligned}
$$

$\mathrm{R}^{2}$ ajustado: 96,75; Erro padrão dos resíduos (Syx): 0,09808; Erro padrão dos resíduos (Syx\%):46,26 e Média dos erros: 0,00726 .

em que:

PS - peso seco da biomassa (do indivíduo), $\mathrm{kg}$;

Dap - diâmetro à altura do peito (1,30 $\mathrm{m}$ do solo);
$\mathrm{H}$ - altura total, m.

Esse modelo utiliza como variáveis independentes o diâmetro a altura do peito (DAP) e a altura total (Ht) das árvores. Nas duas áreas de estudo, nos limites de cada parcela de $50 \times 50 \mathrm{~m}$, foram alocadas sistematicamente três parcelas de 10 x 50 m, paralelas a distância de 10 metros. Nas parcelas foram mensurados todos os indivíduos com DAP $\geq$ a $5 \mathrm{~cm}$, juntamente com suas alturas totais.

A conversão da biomassa em estoque de carbono seguiu o método apresentado pelo IPCC (2003), por meio da Equação 2.

$$
\mathrm{EC}=\mathrm{Fs} \cdot 0,47
$$

em que:

EC - estoque de carbono, $\mathrm{Mg} \mathrm{ha}^{-1}$;

Fs - biomassa seca, $\mathrm{Mg} \mathrm{ha}^{-1}$. Segundo IPCC (2003) 47\% $(0,47)$ da biomassa seca corresponde ao conteúdo de $\mathrm{C}$ total contido na biomassa.

\section{Estimativa da biomassa de raízes}

A determinação da biomassa de raízes em florestas é processo muito laborioso, que demanda muito tempo e, além disso, não é possível recuperar $100 \%$ de todo o sistema radicular para a determinação da biomassa. Assim a biomassa de raízes no presente estudo foi determinada indiretamente por meio de um fator de conversão, proposto por Lima et al. (2006), em que a biomassa seca total das raízes representa em média $30 \%$ da biomassa encontrada na parte aérea dos indivíduos.

\section{Estoque de serapilheira sobre o solo e nutrientes}

Para estimar o estoque de serapilheira utilizou-se um gabarito de madeira de 30 × $30 \mathrm{~cm}$ (área amostral: 0,09 $\mathrm{m}^{2}$ ), sendo coletadas, aleatoriamente, em cada área, 10 amostras na superfície do solo. Após coleta, as amostras foram submetidas à secagem em estufa de circulação forçada a $65^{\circ} \mathrm{C}$, até atingir peso constante. Posteriormente, o material foi pesado, sendo quantificado o estoque de serapilheira com o uso da seguinte expressão:

$$
\text { Estoque de serapilheira }\left(\mathrm{Mg} \mathrm{ha}^{-1}\right)=\frac{\text { peso material }(\mathrm{Mg})}{\text { área do gabarito }(\mathrm{ha})}
$$

Para a quantificação dos teores de carbono orgânico e nutrientes, as 10 amostras de cada estádio sucessional foram unidas duas a duas, perfazendo cinco repetições. Posteriormente, foram moídas e submetidas à digestão sulfúrica para determinação dos teores dos nutrientes $\mathrm{N}, \mathrm{P}, \mathrm{K}$, Ca e Mg, e carbono orgânico, segundo Tedesco et al. (1995). O conteúdo dos nutrientes foi determinado pela multiplicação dos teores pela massa do material estocado. 


\section{Análises estatísticas}

Os dados de biomassa seca, estoque de carbono, serapilheira e nutrientes foram submetidos às análises de homogeneidade da variância (Teste Barttlet), teste de normalidade da variância (Teste de Lilliefors). A seguir foram submetidos à análise de variância com aplicação do teste $\mathrm{F}$ e os valores médios comparados entre si a $5 \%$ de significância por meio do programa Sisvar 4.6.

\section{Resultados e Discussão}

\section{Levantamento florístico e fitossociológico}

$\mathrm{Na}$ área de FSEM, foram identificadas um total de 10 espécies, com indivíduos com diâmetro a altura do peito (DAP) entre 5 e $10 \mathrm{~cm}$ e altura média de $8 \mathrm{~m}$. As famílias verificadas nesse estádio sucessional foram Anacardiaceae, Lecytidaceae, Melastomataceae, Moraceae, Myrsinaceae, Myrtaceae, Rubiaceae, Sapindaceae, Siparunaceae e Urticaceae. As cinco espécies com maior índice de valor de importância (IVI) foram Miconia calvescens DC. $(45,8)$, Astrocaryum aculeatissimum (Schott) Burret (41,4), Siparuna guianensis Aubl. (35,9), Cupanea oblongifolia Mart. (22,3) e Schinus terebinthifolia Raddi (20,7), as quais corresponderam 55,4\% do IVI total.

Já na área de FSEA, foram encontradas 35 espécies arbóreas, com valores médios de DAP e altura, respectivamente, de $15 \mathrm{~cm}$ e de $17,5 \mathrm{~m}$. As famílias verificadas nesse estádio foram Anacardiaceae, Bignoniaceae, Burceraceae, Fabaceae, Erytroxilaceae, Lauraceae, Lecytidaceae, Malvaceae, Meliaceae, Moraceae, Myrtaceae, Nyctaginaceae, Polygonaceae, Rubiaceae, Sapindaceae, Siparunaceae, Solanaceae e Urticaceae. As cinco espécies com maior IVI foram Anadenanthera macrocarpa (Benth.) Brenan (99,3), Trichilia casaretti C.DC. (22,8), Spondias macrocarpa Engl. (17,0), Colubrina glandulosa Perkins $(13,2)$ e Piptadenia gonoacantha (Mart.) J.F.Macbr. (10,2), que juntas corresponderam a $54,2 \%$ do IVI total. Nesse estádio sucessional é importante destacar a dominância relativa $(81,4)$ da espécie Anadenanthera macrocarpa, que correspondeu a $33,1 \%$ do IVI total.

\section{Biomassa e estoque de carbono}

A biomassa total estimada para a comunidade vegetal da FSEA foi três vezes maior que a da FSEM, o que refletiu diretamente nos estoques de carbono (Tabela 2).

A diferença expressiva nos valores de biomassa está diretamente relacionada com a estrutura dos fragmentos, que é reflexo do tempo de sucessão ecológica das áreas, sendo de 65 anos a FSEA e 25 anos a FSEM. As diferentes

Tabela 2. Biomassa e estoque de carbono da parte aérea, raízes e total das áreas de FSEM e FSEA, Pinheiral, RJ

\begin{tabular}{cccccc}
\hline \multirow{2}{*}{$\begin{array}{c}\text { Área } \\
\text { de estudo }\end{array}$} & \multicolumn{2}{c}{ Biomassa } & \multicolumn{3}{c}{ Estoque de carbono } \\
\cline { 2 - 6 } & Parte aérea & Raízes & Total & Parte aérea & Total \\
\cline { 2 - 6 } & \multicolumn{4}{c}{$\left(\mathbf{M g ~ h a}^{-1}\right)$} \\
\hline${ }^{*}$ FSEM & $34,3^{*}$ & $10,3^{*}$ & $44,6^{*}$ & $15,4^{*}$ & $20,9^{*}$ \\
${ }^{*} \mathrm{FSEA}$ & $115,6^{*}$ & $34,7^{*}$ & $150,3^{*}$ & $52,0^{*}$ & $70,6^{*}$ \\
\hline
\end{tabular}

*Valores seguidos com asterisco na coluna indicam diferenças significativas a $5 \%$ de probabilidade pela análise de variância. Legenda: FSEM - floresta secundária estádio médio; FSEA - floresta secundária estádio avançado - *Floresta Estacional Semidecidual. idades sucessionais influíram na dinâmica de crescimento da comunidade vegetal e, consequentemente, nos valores de biomassa. Mueller-Dombois \& Ellenberg (1974) relataram que, durante a trajetória sucessional, ocorrem alterações na composição e na riqueza de espécies vegetais, e aumento na complexidade estrutural da vegetação. Essas mudanças na vegetação das florestas, segundo Guariguata \& Ostertag (2001), também são acompanhadas por alterações no hábitat, com diminuição da intensidade luminosa, incremento de biomassa e disponibilidade de nutrientes no solo.

Com o intuito de evidenciar o potencial que as áreas em processos de sucessão natural avaliadas neste estudo possuem em produzir biomassa, compararam-se os valores aqui estimados com diversos trabalhos realizados em formações florestais da Floresta Atlântica (Tabela 3). Contudo, é importante ressaltar que os trabalhos consultados foram realizados em diferentes fisionomias (Floresta Ombrófilo e Floresta Estacional), com diferentes estádios sucessionais, conservadas ou preservadas.

Os valores de biomassa acima do solo estimados $(34,3$ e $115,6 \mathrm{Mg} \mathrm{ha}^{-1}$ ) se encontram na faixa dos encontrados nas diversas formações florestais da Floresta Atlântica, os quais variaram de 12,3 a $663,5 \mathrm{Mg} \mathrm{ha}^{-1}$ (Tabela 3). Os valores deste estudo também se encontram entre os verificados por Melo \& Durigan (2006), avaliando a fixação de carbono em plantios para restauração em áreas ciliares, no Vale do Paranapanema, SP.Os autores quantificaram para 24 áreas com diferentes idades de plantio (1,1 a 18 anos) valores de biomassa entre 1,2 e 188,3 $\mathrm{Mg} \mathrm{ha}^{-1}$ (Tabela 3).

Quando comparados os valores de biomassa com os quantificados em mesma fisionomia Floresta Estacional é possível observar que, de maneira geral, independente se a formação se encontra conservada ou preservada, os valores se encontram na faixa de 12,3 a 437,0 $\mathrm{Mg} \mathrm{ha}^{-1}$ (Tabela 3). Mesmo padrão também é observado quando comparam-se os valores desse estudo com áreas de mesma fisionomia, mas com diferentes idades sucessionais (20 a 70 anos), estando os valores entre 12,3 a 298,1 $\mathrm{Mg} \mathrm{ha}^{-1}$ (Tabela 3).

Ao comparar os dados de biomassa desse estudo com trabalhos realizados em mesma fisionomia, Floresta Estacional Semidecidual Submontana, com diferentes idades sucessionais, é possível observar que os valores apresentam a mesma magnitude.

As diferenças encontradas nas estimativas da biomassa estão possivelmente relacionadas com a idade sucessional, com as variações de altura, de DAP, do número de indivíduos por hectare e composição florística, como descrito nos trabalhos de Chaves et al. (2005) e Nogueira et al. (2008). Além disso, estudos realizados em florestas tropicais relatam que as variações nas estimativas de biomassa são decorrentes de diferenças regionais de fertilidade do solo, topografia e alterações antrópicas (Urquiza-Haas et al., 2007; Alves et al., 2010), além de características da comunidade florestal, como as variações da altura do dossel, densidade média da madeira e composição florística (Nogueira et al., 2008).

Em relação aos valores do estoque de carbono da biomassa aérea (Tabela 3), assim como os observados para a biomassa, esses são similares aos quantificados em áreas de Floresta Atlântica, os quais variaram de 6,18 a $167,14 \mathrm{Mg} \mathrm{ha}^{-1} \mathrm{C}$. Os 
Tabela 3. Estimativa de biomassa $\left(\mathrm{Mg} \mathrm{ha}^{-1}\right)$ em diferentes formações florestais da Floresta Atlântica

\begin{tabular}{|c|c|c|c|}
\hline Local & Formação florestal & Biomassa & Autor \\
\hline Pinheiral, RJ & $\begin{array}{c}\text { F.E.S. Submontana } \\
\text { (25 e } 65 \text { anos de sucessão) }\end{array}$ & 33,4 e 115,6 & Presente trabalho \\
\hline Médio Rio Doce, MG & $\begin{array}{l}\text { F.E.S. Submontana } \\
\text { (25 e } 27 \text { anos de sucessão) }\end{array}$ & 57,5 e 112,0 & Drumond et al. (1997) \\
\hline Oratórios, MG & $\begin{array}{l}\text { F.E.S. Submontana } \\
\text { (34 e } 80 \text { anos de sucessão) }\end{array}$ & $64,0-172,7$ & Lima et al. (2006) \\
\hline Caratinga e Bom Jesus do Galho, MG & $\begin{array}{l}\text { F.E.S. Submontana } \\
\text { (20 anos de sucessão) }\end{array}$ & $71,74-158,77$ & Souza et al. (2011) \\
\hline Caratinga e Bom Jesus do Galho, MG & $\begin{array}{l}\text { F.E.S. Submontana } \\
\text { (20 anos de sucessão) }\end{array}$ & $73,09-150,0$ & Souza et al. (2012) \\
\hline Viçosa, MG & $\begin{array}{l}\text { F.E.S. Montana } \\
\text { (100 anos, conservada) }\end{array}$ & $106,5-334,29$ & Ribeiro et al. (2009a) \\
\hline Viçosa, MG & $\begin{array}{c}\text { F.E.S. Montana } \\
\text { (30 anos de sucessão) }\end{array}$ & $12,3-66,06$ & Ribeiro et al. (2010) \\
\hline Reserva da Vale, Linhares, ES & $\begin{array}{l}\text { F.E.S. } \\
\text { (preservada) }\end{array}$ & $241,0-437,0$ & Rolim et al. (2005) \\
\hline Bacia do Paranapanema, SP & $\begin{array}{c}\text { F.E.S. } \\
\text { (23 e } 28 \text { anos de sucessão) }\end{array}$ & 58,2 e 298,1 & Melo \& Durigan (2006) \\
\hline Bacia do Paranapanema, SP & $\begin{array}{l}\text { F.E.S. } \\
\text { (plantios de restauração) }\end{array}$ & $1,2-188,3$ & Melo \& Durigan (2006) \\
\hline Itaara, RS & $\begin{array}{l}\text { F.E.D. } \\
\text { (70 anos de sucessão) }\end{array}$ & 210,0 & Vogel et al. (2013) \\
\hline Araucárias, PR & $\begin{array}{l}\text { F.O.M. Aluvial } \\
\text { (conservada) }\end{array}$ & 170,0 & Socher et al. (2008) \\
\hline $\begin{array}{l}\text { Parque Estadual do Desengano, } \\
\text { Santa Maria Madalena, RJ }\end{array}$ & $\begin{array}{l}\text { F.O.D. Montana } \\
\text { (40 anos de sucessão) }\end{array}$ & $148,4-167,9$ & Cunha et al. (2009) \\
\hline $\begin{array}{l}\text { R. Ecológica de Guapiaçu e Parque Estadual } \\
\text { da Serra dos Órgãos, RJ }\end{array}$ & $\begin{array}{l}\text { F.O.D. Montana e Submontana } \\
\text { (preservada e secundária) }\end{array}$ & 250,4 e 313,5 & Lindner \& Satter (2012) \\
\hline General Carneiro, PR & $\begin{array}{c}\text { F.O.M. Montana } \\
\text { (diferentes estádios sucessionais) }\end{array}$ & 250,90 & Watzlawick et al. (2012) \\
\hline $\begin{array}{l}\text { Parque Estadual da Serra do Mar e Serra da } \\
\text { Bocaína, SP }\end{array}$ & $\begin{array}{l}\text { F.O.D. } \\
\text { (várias formações preservadas) }\end{array}$ & $163,5-271,3$ & Alves et al. (2010) \\
\hline Parque Nacional da Serra dos Órgãos, RJ & $\begin{array}{c}\text { F.O.D. } \\
\text { (várias formações preservadas) }\end{array}$ & $276,3-663,5$ & Lindner (2010) \\
\hline APA Rio Macacú, Cachoeiras do Macacú, RJ & $\begin{array}{c}\text { F.O.D. } \\
\text { (diferentes estádios sucessionais) }\end{array}$ & $36,0-199,0$ & Lima (2010) \\
\hline
\end{tabular}

Legenda: F.E.S.: Floresta Estacional Semidecidual; F.E.D.: Floresta Estacional Decidual; F.O.M.: Floresta Ombrófilo Mista; F.O.D.: Floresta Ombrófilo Densa.

valores estimados de estoque de carbono em áreas com mesma fisionomia, Floresta Estacional Semidecidual Submontana, variaram de 28,0 a 79,38 $\mathrm{Mg} \mathrm{ha}^{-1}$ de $\mathrm{C}$.

Estimando o estoque de carbono em mesma fisionomia, em Oratórios, MG, Lima et al. (2003), constataram para áreas com 34 e 80 anos de sucessão, respectivamente, valores de 28 e $29 \mathrm{Mg} \mathrm{ha}^{-1} \mathrm{C}$. Avaliando o estoque de carbono em área de Floresta Atlântica, em Cruzeiro, SP, Coutinho et al. (2010) verificou na área de floresta estacional semidecidual submontana, com 37 anos de sucessão, valor estimado de estoque de 45,4 $\mathrm{Mg} \mathrm{ha}^{-1} \mathrm{C}$. Já Souza et al. (2011) quantificando o estoque de carbono em mesma fisionomia florestal, com 20 anos de sucessão, verificaram valores variando de $35,87 \mathrm{Mg}$ $\mathrm{ha}^{-1}$ de $\mathrm{C}$ na área em estádio médio e $79,38 \mathrm{Mg} \mathrm{ha}^{-1} \mathrm{C}$ na área em estádio avançado.

Outros trabalhos realizados em floresta estacional semidecidual, como os de Melo \& Durigan (2006) avaliando a fixação de carbono em 24 áreas reflorestadas no Vale do Paranapanema, SP, encontraram valores de estoque entre 0,6 a 94,1 $\mathrm{Mg} \mathrm{ha}^{-1} \mathrm{C}$. Os mesmos autores, estudando duas florestas secundárias com 23 e 28 anos de sucessão estimaram estoques de carbono, respectivamente, de 29,1 e 149,0 $\mathrm{Mg} \mathrm{ha}^{-1} \mathrm{C}$. Ribeiro et al. (2009b) quantificaram valores médios de carbono de $83,34 \mathrm{Mg} \mathrm{ha}^{-1} \mathrm{C}$, em uma fragmento de Floresta Atlântica com pelo menos 100 anos sem intervenção antrópica em estádio avançado de sucessão. Já Ribeiro et al. (2010), quantificando a biomassa aérea e o estoque de carbono de uma área em estádio médio, com 35 anos em Minas Gerais, verificaram valores médios de estoque de carbono de 19,5 $\mathrm{Mg} \mathrm{ha}^{-1} \mathrm{C}$.

Outro ponto a ser destacado é o potencial do sistema radicular em produzir biomassa e estocar C. Na FSEM o sistema radicular apresentou um estoque de $\mathrm{C}$ de $6,2 \mathrm{Mg} \mathrm{ha}^{-1}$ e na área de FSEA estoque de $\mathrm{C}$ de $18,5 \mathrm{Mg} \mathrm{ha}^{-1}$. Paiva \& Faria. (2007) ao realizarem um estudo do estoque de $\mathrm{C}$ sob solo de Cerrado sensu stricto revelam que o sistema radicular foi responsável por $7,6 \%$ do $\mathrm{C}$ do solo, os mesmos autores quantificaram até uma profundidade de $2 \mathrm{~m}$ uma biomassa do sistema radicular de $46,6 \mathrm{Mg} \mathrm{ha}^{-1}$ e um estoque de $\mathrm{C}$ de 22,3 $\mathrm{Mg} \mathrm{ha}^{-1}$. Nas regiões tropicais os solos sob florestas apresentam um potencial de sequestrar $\mathrm{C}$, devido à biomassa depositada na forma de manta orgânica e de raízes mortas (Lal et al., 2005).

Em função do exposto, é possível evidenciar que os valores do estoque de biomassa, nas diferentes formações florestais avaliadas neste estudo, e nos trabalhos realizados nas diversas formações florestais da Floresta Atlântica, seguem um padrão de aumento em função do estádio sucessional da floresta. Outra questão que deve ser considerada está relacionada aos valores de biomassa e carbono serem próximos aos verificados em diversas formações florestais, inclusive os plantios de restauração citados. Esse padrão indica que as florestas aqui estudadas, mesmo em processos de restauração passiva, são de grande relevância no contexto da qualidade ambiental, pois uma vez restaurada sua funcionalidade serão capazes de gerar serviços ecossistêmicos de provisão como a produção 
e qualidade de água e a ciclagem de nutrientes, bem como serviços de regulação ambiental como controle de erosão e de enchentes. Além disso, no contexto das mudanças climáticas, a conservação de áreas secundárias se torna necessário, pois foi evidenciada sua capacidade de sequestrar carbono atmosférico.

\section{Estoque de serapilheira}

O maior estoque de serapilheira foi verificado na área de FSEA, acumulando em média $17,50 \mathrm{Mg} \mathrm{ha}^{-1}$, enquanto na FSEM o estoque estimado foi de 7,66 $\mathrm{Mg} \mathrm{ha}^{-1}$ (Figura 1).

Os maiores valores do estoque de serapilheira na FSEA podem estar relacionados com o estádio sucessional avançado no qual a área se encontra, sendo caracterizada com maior densidade de indivíduos, maior número de espécies, bem como maior biomassa. Essas características da vegetação, possivelmente, estão influindo na deposição de serapilheira e, consequentemente, no acúmulo de material na superfície do solo. Maior deposição de serapilheira foi constatada por Machado (2011), estudando as mesmas áreas deste estudo, o que corrobora a hipótese antes mencionada. Além da influência sucessional na dinâmica do estoque de serapilheira, Caldeira et al. (2008) relataram vários outros fatores que influem na dinâmica de estoque como procedência, espécie, fisionomia florestal e época de coleta. Outros fatores também afetam o acúmulo do material na superfície do solo, como os ambientais (temperatura e umidade), qualidade nutricional do material formador da serapilheira e ação de organismos e microrganismos do solo (Correia \& Andrade, 2008).

Dados apresentados por Borém \& Ramos (2002), mostraram que o estoque de serapilheira em algumas florestas tropicais úmidas do Brasil variou de 5,6 a 31,2 $\mathrm{Mg} \mathrm{ha}^{-1}$. Já Correia \& Andrade (2008), relataram que o acúmulo de serapilheira em ambientes tropicais variou de 3,6 a 12,4 $\mathrm{Mg} \mathrm{ha}^{-1}$. Os valores de estoque de serapilheira desse estudo se assemelham aos verificados nos trabalhos supracitados, mostrando a evolução no processo sucessional das áreas.

Para os valores dos teores e conteúdos de carbono orgânico e nutrientes, de maneira geral, verificaram-se diferenças entre as áreas (Tabela 4).

Com relação ao carbono orgânico, verificaram-se maiores teores e conteúdos na FSEA, sendo o valor do conteúdo

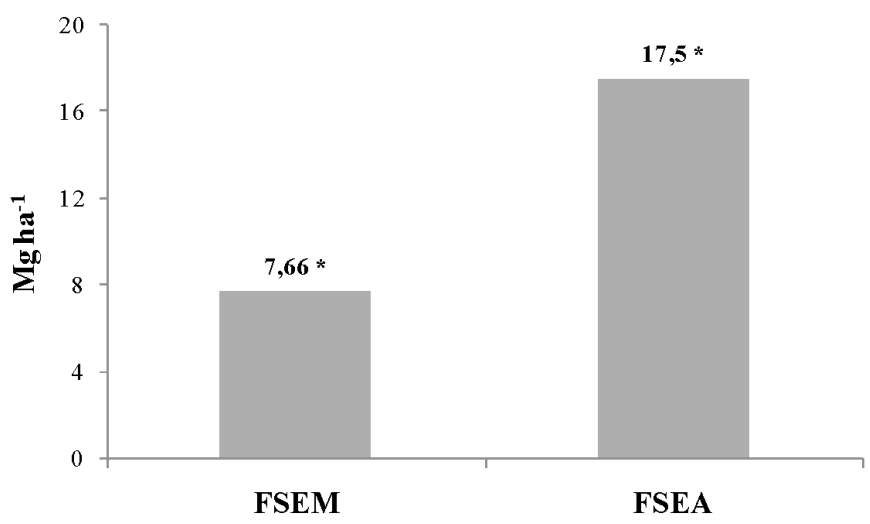

* diferença significativa a $5 \%$ de probabilidade pela análise de variância. Legenda: *FSEM: floresta secundária em estádio médio; *FSEA: floresta secundaria em estádio avançado ( ${ }^{*}$ Floresta Estacional Semidecidual).

Figura 1. Estoque de serapilheira nas áreas de floresta secundária, em Pinheiral, RJ
Tabela 4. Teores e conteúdos de carbono e nutrientes na serapilheira acumulada nas áreas de FSEM e FSEA, em Pinheiral, RJ

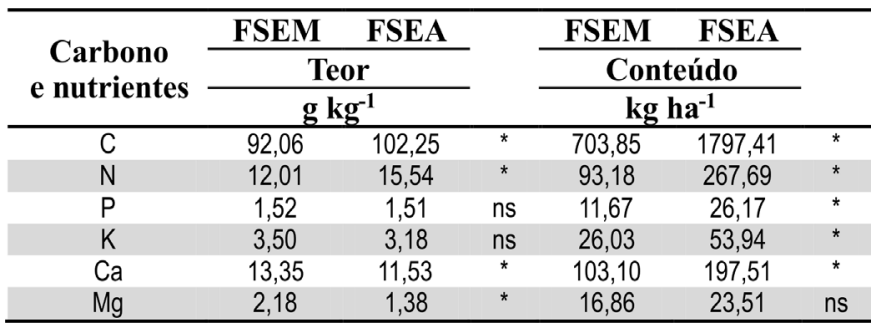

( ${ }^{*}$ diferença significativa a $5 \%$ de probabilidade pela análise de variância; n.s.: não significativo). Legenda: *FSEM - floresta secundária em estádio médio; *FSEA - floresta secundária em estádio avançado. ${ }^{*}$ Floresta Estacional Semidecidual.

$\left(1797,41 \mathrm{~kg} \mathrm{ha}^{-1}\right)$ aproximadamente três vezes maiores que o da FSEM $\left(703,85 \mathrm{~kg} \mathrm{ha}^{-1}\right)$. Essa expressiva diferença está diretamente relacionada com o maior estoque de serapilheira na área FSEA. Valores próximos aos encontrados na área de FSEA foram constatados por Caldeira et al. (2008) ao estudarem diferentes estádios sucessionais de uma floresta ombrófila densa em Blumenau, SC. Os autores verificaram valores de carbono orgânico de $1470 \mathrm{~kg} \mathrm{ha}^{-1}$ no estádio inicial, $1650 \mathrm{~kg}$ $\mathrm{ha}^{-1}$ no estádio médio e $1500 \mathrm{~kg} \mathrm{ha}^{-1}$ no estádio avançado. Outros trabalhos, como os de Cunha et al. (2009) avaliando fragmentos preservados de floresta ombrófila densa montana na região norte do Rio de Janeiro, constataram conteúdo de carbono superiores aos deste estudo, com valores entre $2900 \mathrm{e}$ $3670 \mathrm{~kg} \mathrm{ha}^{-1}$. Assim, as diferenças entre os valores de carbono entre este trabalho e os de Cunha et al. (2009) podem estar relacionadas com o estádio sucessional em que as áreas se encontram. Neste sentido, é possível inferir que, mesmo os valores de carbono orgânico terem sido inferiores que os estudos de Cunha et al. (2009), as áreas aumentam o conteúdo de carbono em função do avanço sucessional.

A partir dos valores dos teores e conteúdos de nutrientes, observou-se que a serapilheira é uma importante via de transferência de N, Ca e Mg para o solo, sendo constatadas diferenças, principalmente, para os teores desses elementos entre as áreas. $\mathrm{Na}$ área de FSEA os teores de $\mathrm{N}$ foram superiores aos encontrados na FSEM. Já os teores de $\mathrm{Ca}$ e $\mathrm{Mg}$ foram estatisticamente maiores na FSEM. Os teores de $\mathrm{P}$ e $\mathrm{K}$ entre as áreas não se diferiram.

Para o conteúdo de nutrientes, de maneira geral, os maiores valores foram verificados na FSEA. Somente não foi observada diferença para o conteúdo de Mg. Maiores valores do conteúdo na FSEA para a maioria dos nutrientes se devem pelo maior valor de estoque nessa área. Estudando diferentes estádios sucessionais de uma floresta decidual no RS, Brun et al. (2004) relataram que o retorno de nutrientes por meio da serapilheira possui maior razão de proporcionalidade com a quantidade de serapilheira depositada do que com os teores dos nutrientes da mesma, mesmo padrão que o deste estudo.

$\mathrm{Na}$ FSEA, dentre os nutrientes avaliados, o $\mathrm{N}$ foi aquele que apresentou maior teor e conteúdo. Além disso, o teor e conteúdo de $\mathrm{N}$ entre as áreas foram maiores na FSEA. Maior estoque de $\mathrm{N}$ também foi encontrado por Cunha et al. (2009), ao estudarem dois fragmentos de Mata Atlântica no RJ, e por Caldeira et al. (2008), quantificando nutrientes da serapilheira estocada em diferentes estádios sucessionais de uma floresta ombrófila densa em Santa Catarina. Quanto a diferença nos 
valores de $\mathrm{N}$ entre os estádios sucessionais, Amazonas et al. (2011), estudando a dinâmica de nitrogênio em florestas secundárias com diferentes idades em São Paulo, ratificam os resultados deste estudo, ao constatarem maiores teores de $\mathrm{N}$ foliar conforme o avanço sucessional, constatando valores de $2,57 \%$ na floresta em restauração de 21 anos, $2,87 \%$ na floresta em processo de restauração de 52 anos e 2,99\% na floresta natural.

$\mathrm{O}$ maior teor de $\mathrm{N}$ na FSEA pode estar associado à expressiva estrutura horizontal da espécie Leguminosae (Fabaceae) Anadenanthera macrocarpa, a qual apresentou maior índice de valor de importância. Segundo Franco et al. (1992), essa espécie é conhecida pela sua capacidade de adicionar $\mathrm{N}$ via fixação biológica, o que possivelmente contribuiu com maior teor desse elemento na serapilheira. Ao estudar o acúmulo e decomposição da serapilheira em quatro formações florestais, Cunha Neto et al. (2013), também constataram maiores teores e conteúdos de $\mathrm{N}$ na formação florestal da Leguminosae Acacia mangium, e relacionaram os maiores valores nessa formação à capacidade da espécie em fixar nitrogênio. Já Davidson et al. (2007), relatam que as florestas tropicais são limitadas por $\mathrm{N}$ nas etapas iniciais da sucessão, com maior ciclagem interna e perda reduzida desse nutriente. Assim, essas evidências acima podem explicar os maiores valores de $\mathrm{N}$ na FSEA e os menores na FSEM.

Diferindo da expressividade do elemento $\mathrm{N}$ na FSEA, na FSEM o Ca se configurou como o nutriente mais abundante. Nesse estádio sucessional os teores de Mg também foram superiores que na FSEA. Os maiores teores desses elementos na FSEM podem estar relacionados à contribuição da fração folhas no material adicionado ao solo. Estudando a deposição de serapilheira na mesma área desse estudo, Machado (2011), constatou que a fração foliar na floresta em estádio médio representou valor de $80,7 \%$, ao passo que na FSEA as folhas representaram contribuição relativa de $66 \%$. Segundo Guariguata \& Ostertag (2001), o padrão de ciclagem de nutrientes em florestas iniciais é de acúmulo de nutrientes nas folhas e nas raízes, com alta renovação de nutrientes, ao passo que em florestas em fase posterior de sucessão os nutrientes são imobilizados no tronco, sendo a renovação mais lenta. Esse padrão também foi verificado por Borém \& Ramos (2002), ao estudarem o estoque de nutrientes em áreas com diferentes históricos de perturbação. As autoras explicaram que a menor quantidade de nutrientes no solo e na serapilheira na área menos alterada foi resultado da característica da vegetação a qual a área se encontra, estando próxima ao clímax, em que imobilizam grande quantidade de nutrientes na biomassa, reduzindo ao mínimo os seus níveis no solo.

Para os teores e conteúdos de nutrientes, a quantidade na FSEM obedeceu a ordem decrescente de $\mathrm{Ca}>\mathrm{N}>\mathrm{K}>\mathrm{Mg}>$ P.Na FSEA, a ordem decrescente se diferenciou, sendo esta $\mathrm{N}$ $>\mathrm{Ca}>\mathrm{K}>\mathrm{P}>\mathrm{Mg}$ (Tabela 4). Viera et al. (2010) verificaram mesma sequência que a observada para área de FSEM, ao estudarem nutrientes na serapilheira em um fragmento de floresta estacional decidual em Itaara, RJ. Já Caldeira et al. (2008) e Cunha et al. (2009), constataram a mesma ordem identificada para a área de FSEA. No entanto, outra sequência na ordem decrescente dos valores totais dos macronutrientes também foi observada nos trabalhos de Borém \& Ramos (2002), estudando a variação estacional e topográfica de nutrientes na serapilheira de um fragmento de Floresta Atlântica, no RJ, em que os autores constataram a seguinte sequência $\mathrm{Ca}>\mathrm{Mg}>\mathrm{N}>\mathrm{K}>\mathrm{P}$.

Quanto ao estoque dos nutrientes da serapilheira, os valores do presente estudo se encontram na faixa dos trabalhos realizados e apresentados por Borém \& Ramos (2002) e Viera et al. (2010). No entanto, os valores podem ser considerados altos quando comparados com os estudos de Caldeira et al. (2008) os quais avaliaram também diferentes estádios sucessionais. Esses autores verificaram valores de estoque de $\mathrm{N}$ variando de 67,45 a $88,70 \mathrm{~kg} \mathrm{ha}^{-1}$, valores de P entre 2,61 a $2,78 \mathrm{~kg} \mathrm{ha}^{-1}$, de K entre 9,9 a 11,77 $\mathrm{kg} \mathrm{ha}^{-1}$, de Ca entre 40,2 a 60,9 $\mathrm{kg} \mathrm{ha}^{-1}$ e de $\mathrm{Mg}$ entre 12,85 a 13,87 $\mathrm{kg} \mathrm{ha}^{-1}$. No entanto, uma possível explicação para essas diferenças se deve ao maior estoque de serapilheira que foi verificado nesse estudo, sendo também superior aos valores encontrados por Caldeira et al. (2008).

\section{Conclusões}

O tempo de sucessão influenciou na acumulação de biomassa e carbono da biomassa, bem como nos estoques de serapilheira, carbono e nutrientes da serapilheira.

A biomassa e o estoque de carbono da biomassa foram superiores na FSEA.

$O$ estoque de serapilheira, de carbono e nutrientes da serapilheira foram maiores na FSEA.

A serapilheira se mostrou como uma importante via de transferência de nutrientes para o solo, destacando-se o $\mathrm{N}$ na FESA e o Ca na FSEM.

\section{Agradecimentos}

Os autores agradecem ao Programa de Pós Graduação em Ciências Ambientais e Florestais da UFRRJ, ao CNPq, à FAPERJ e ao IFRJ - Câmpus Nilo Peçanha - Pinheiral -RJ.

\section{Literatura Citada}

Alves, L. F.; Vieira, S. A.; Scaranello, M. A. S.; Camargo, P.B.; Santos, F. A. M.; Joly, C. A.; Martinelli, L. A. Forest structure and live aboveground biomass along an elevational gradient of tropical forest (Brazil). Forest Ecology and Management, v.260, n.5, p.679-691, 2010.Dez.2013. $<\mathrm{http}$ //dx.doi.org/10.1016/j.foreco.2010.05.023>.

Amazonas, N.; Martinelli, L. A.; Piccolo, M. C.; Rodrigues, R. R. Nitrogen dynamics during ecosytem development in tropical forest restoration.Forest Ecology and Management, v.262, n.8, p.1551-1557, 2012. <http://dx.doi.org/10.1016/j. foreco.2011.07.003>.

Borém, R. A. T.; Ramos, D. P.Variação estacional e topográfica de nutrientes na serapilheira de um fragmento de mata atlântica. Cerne, v.8, n.2, p.42-59, 2002. <http://www. redalyc.org/pdf/744/74480204.pdf>. 10 Dez.2013.

Brun, E. J. Biomassa e nutrientes na floresta estacional decidual em Santa Tereza, RS. Santa Maria: Universidade Federal de Santa Maria, 2004. 126p.Dissertação Mestrado. <http:// www.bibliotecaflorestal.ufv.br/handle/123456789/4973>. 13 Dez. 2013. 
Caldeira, M. V.W.; Vitorino, M. D.;Schaadt, S. S.; Moraes, E.;Balbinot, R. Quantificação de serapilheira e de nutrientes em uma Floresta Ombrófila Densa. Semina: Ciências Agrárias, v.29, n.1, p.53-68, 2008. Dez. 2013. <http:// dx.doi.org/10.5433/1679-0359.2008v29n1p5>.

Celentano, D; Zahawi, R. A.; Finegan, B.; Cole, R. J.; Holl, K. D. Litterfall dynamics under different Tropical Forest restoration strategies in Costa Rica. Biotropica, v.43, n.3, p.279-287. <http://dx.doi.org/10.1111 j. $1744-7429.2010 .00688 . \mathrm{x}>$.

Chaves, J.; Andalo, C.; Brown, S.; Cairns, M. A.; Chambers, J. Q.; Eamus, D.; Fölster, H.; Fromard, F.; Higuchi, N.; Kira, T.; Lescure, J.-P.; Nelson, B. W.; Ogawa, H.; Puig, H.; Riéra, B.; Yamakura, T. Tree alometriy and improved estimation of carbon stocks and balance in tropical forests. Oecologia, v.145, n.1, p.87-99, 2005. <http://dx.doi. org/10.1007/s00442-005-0100x>.

Cheng, C.; Wang, R., Jiang J. Variation of soil fertility and carbon sequestration by planting Hevea brasiliensis in Hainan Island, China. Journal of Environmental Sciences. v.19, p.348-352, 2007. <http://dx.doi.org/10.1016/S1001-0742(07)60057-6>.

Correia, M. E. F; Andrade, A. G. Formação de serapilheira e ciclagem de nutrientes. In: Santos, G.A.; Camargo, F.A. de. (Eds.). Fundamentos da matéria orgânica do solo: ecossistemas tropicais e subtropicais. 2 ed. Porto Alegre: Metrópole, 2008. p.137-158.

Coutinho; R. P.; Urquiaga, S.; Boddey, R. M.; Alves, B. J. R.; Torres, A. Q. A.; Jantalia, C. P.Estoques de carbono e emissão de $\mathrm{N}_{2} \mathrm{O}$ em diferentes usos do solo na Mata Atlântica. Pesquisa Agropecuária Brasileira, v.45, n.2, p.195-203, 2010. <http:// dx.doi.org/10.1590/S0100-204X2010000200011>.

Cunha Neto, F. V.; Leles, P. S. S.; Pereira, M. G.; Bellumath, V. G. H.; Alonso, J. M. Acúmulo e decomposição da serapilheira em quatro formações florestais. Revista Ciência Florestal, v.23, n.3, p.378-387, 2013. <http:// dx.doi.org/10.5902/1980509810549>.

Cunha; G. M., Gama-Rodrigues; A. C. Gama-Rodrigues; E. F. Velloso; A. C. X. Biomassa e Estoque de Carbono e Nutrientes em Florestas Montanas da Mata Atlântica na Região Norte do Estado do Rio de Janeiro. Revista Brasileira de Ciência do Solo, v.33, n.5, p.1175-1185, 2009. $<$ http://dx.doi.org/10.1590/S0100-06832009000500011>.

Davidson, E. A.; Carvalho, C. J. R.; Figueira, A. M.; Ishida, F. Y.; Ometto, J. P. H. B.; Nardoto, G. B.; Sabá, R. T.; Hayashi, S. N.; Leal, E. C.; Vieira, I. C. G.; Martinelli, L. A Recuperation of nitrogen cycling in Amazonian forests following agricultural abandonment. Nature, v.447, n.7147, p.995-998, 2007. <http://dx.doi.org/10.1038/ nature $05900>$.

Drumond, M. A.; Barros, N. F.; Souza, A. L.; Silva, A. F. Distribuição de Biomassa e de nutrientes em diferentes coberturas florestais e pastagens na região do Médio Rio Doce - MG. Revista árvore, v.21, n.2 p.187-199, 1997. $<\mathrm{http}$ ://dx.doi.org/10.1590/S0100-06832009000500011>.

Empresa Brasileira de Pesquisa Agropecuária - Embrapa. Centro Nacional de Pesquisa de Solos. Manual de métodos de análise de solo. 2.ed. Rio de Janeiro: Embrapa-CNPS, 1997. 212 p. (Embrapa-CNPS. Documentos, 1).
Food and Agriculture Organization of the United Nations FAO. State of the World's Forests. Rome: FAO, 2011. 119 p. $<$ http://www.fao.org/forestry/sofo/en>.

Franco, A. A.; Campello, E. F.; Silva, E. R.; Faria, S. M. Revegetação de solos degradados. Embrapa - CNPAB, 1992. 9p. (Comunicado Técnico, 9).

Guariguata, M. R.; Ostertag, R. Neotropical secondary forest succession: changes in structural and functional characteristics. Forest Ecology and Management, v.148, n.3, p.185-206, 2001. $<$ http://dx.doi.org/10.1016/S0378-1127(00)00535-1>.

Henriques, F. S. The uncertain future of tropical Forests. Revista de Ciências Agrárias, v.33, n.2, p.265-271, 2010. <http://www. scielo.mec.pt/scielo.php?script=sci_arttext\&pid=S0871018X2010000200024\&lng=en\&nrm=iso $>.02$ Dez.2013.

Intergovernmental Panel of Climate Change - IPCC. Good practice for land-use change and forestry. Japan. Institute for Global Environmental Strategies, 2003. <http://www. ipcenggip.iges.or.jp/public/gpglulucf/gpglulucf_files/ GPG_LULUCF_FULL.pdf>. 02 Dez. 2013.

Lal, R. Forest soils and carbon sequestration.Forest Ecology and Management, v.220, n.1/3, p.242-258, 2005. <http:// dx.doi.org/10.1016/j.foreco.2005.08.015>.

Lima, J. A. de S. Estimativas da biomassa acima do solo de florestas secundárias da área de proteção ambiental Rio Macacu (RJ). Rio de Janeiro: Embrapa Solos, 2010. 28 p. (Embrapa Solos. Boletim de Pesquisa e Desenvolvimento, 163). <http://ainfo.cnptia.embrapa.br/digital/bitstream/ item/36066/1/Bol-PD-163.pdf>. 12 Dez. 2013.

Lima, J. A. S.; Carmo, C. A. F. S.; Kindel, A.; Motta, P.E. F. Estimativa de biomassa e carbono de uma floresta secundária em Minas Gerais. Rio de Janeiro: Embrapa Solos, 2003. 18 p. (Embrapa Solos. Boletim de Pesquisa e Desenvolvimento; n.20) <http://ainfo.cnptia.embrapa.br/ digital/bitstream/CNPS/11597/1/bpd20_2003_estimativa. pdf>. 12 Dez. 2013.

Lima, J. A. S.; Kindel, A.; Carmo, C. A. F. S.; Motta, P. E. F. Composição, estrutura e biomassa de fragmentos florestais. In: Alvarenga, A. P.; Carmo, C. A. F. S. (Eds.). Sequestro de carbono: quantificação em seringais de cultivo e na vegetação natural. Viçosa: UFV, 2006. p.112-134.

Lindner, A. Biomass storage and stand structure in a conservation unit in the Atlantic Rainforest: the role of big trees. Ecological Engineering, v.36, n.12, p.1769-1773, 2010. <http://dx.doi.org/10.1016/j.ecoleng.2010.07.017>.

Lindner, A.; Satter, D. Biomass estimations in forests of different disturbance history in the Atlantic Forest of Rio de Janeiro, Brazil. New Forests, v.43, n.3, p.287-301, 2012. $<$ http://dx.doi.org/10.1007/s11056-011-9281-9>.

Machado, D. L. Atributos indicadores da dinâmica sucessional em framento de Mata Atlântica na região do médio vale do Paraíba do Sul, Pinheiral, Rio de Janeiro. Seropédica: Universidade Federal Rural do Rio de Janeiro, 2011. 103p. Dissertação Mestrado.

Melo, A. C. G.; Durigan, G. Fixação de carbono em reflorestamentos de restauração e em matas ciliares nativas no Vale do Paranapanema, SP, Brasil. Scientia Forestalis, n.71, p.149-154, 2006. <http://www.ipef.br/publicacoes/ scientia/nr71/cap15.pdf>. 02 Dez. 2013. 
Menezes, C. E. G. Integridade de paisagem, manejo e atributos do solo no Médio Vale do Paraíba do Sul, Pinheiral-RJ. Seropédica: Universidade Federal Rural do Rio de Janeiro, 2008. 172p. Tese Doutorado.

Mueller-Dombois, D.; Ellenberg, H. Aims and methods of vegetation ecology. New York: John Wiley \& Sons, 1974. $547 \mathrm{p}$.

Nogueira, E. M.; Nelson, B. W.; Fearnside, P. M.; França, M. B.; Oliveira, A. C. A. Tree height in Brazil's "arc of deforestation": shorter trees in south and southwest Amazonia imply lower biomass. Forest Ecology and Management, v.255, n.7, p.2963-2972, 2008. <http:// dx.doi.org/10.1016/j.foreco.2008.02.002>.

Paiva, A. O.; Faria, G. E. Estoque de carbono do solo sob cerrado sensu stricto no Distrito Federal, Brasil. Revista Trópica - Ciências Agrárias e Biológicas, v.1, n.1, p.59, 2007. <http://www.ccaa.ufma.br/revistatropica/Artigos nr1/agronomia/EstoqueDeCarbonoDoSolo_agro_art.pdf $>$. 12 Dez. 2013.

Ribeiro, M. C.; Metzger, J. P.; Martensen, A. C.; Ponzoni, F. J.; Hirota, M. M. The Brazilian Atlantic Forest: How much is left, and how is the remaining forest distributed? Implications for conservation. Biological Conservation, v.143, n.6, p.1141-1153, 2009a. <http://dx.doi. org/10.1016/j.biocon.2009.02.021>.

Ribeiro, S. C.; Jacovine, L. A. G.; Soares, C. P. B.; Martins, S. V.; Souza, A. L.; Nardelli, A. M. B. Quantificação de biomassa e estimativa de estoque de carbono em uma floresta madura no município de Viçosa, Minas Gerais. Revista Árvore, Viçosa-MG, v.33, n.5, p.917-926, 2009 b. $<$ http://dx.doi.org/10.1590/S0100-67622009000500014>.

Ribeiro, S. C.; Jacovine, L. A. G.; Soares, C. P. B.; Martins, S. V.; Nardelli; A. M. B.; Souza, A. L. Quantificação de biomassa e estimativa de estoque de carbono em uma capoeira da Zona da Mata Mineira. Revista Árvore, v.34, n.3, p.495-504, 2010. <http://dx.doi.org/10.1590/S010067622010000300013>.

Rizzini, C. T. Tratado de fitogeografia do Brasil. v.2. Aspectos ecológicos. São Paulo: Hucitec/Edusp, 1979. 374p.

Rolim, S. G.; Jesus, R. M.; Nascimento, H. E. M.; Couto, H. T. Z.; Chambers, J. Q. Biomass change in an Atlantic tropical moist forest: the ENSO effect in permanent sample plots over a 22-year period. Oecologia, v.142, p.238-246, 2005. $<$ http://dx.doi.org/10.1007/s00442-004-1717-x>.

Scolforo, J. R.; Rufini, A. L.; Mello, J. M.; Trugilho, P. F.; Oliveira, A. D.; Silva, C. P. Equações para o peso de matéria seca das fisionomias, em Minas Gerias. In: Scolforo, J. R.; Oliveira, A. D.; Acerbi Júnior, F. W.(Eds.). Inventário florestal de Minas Gerais - equações de volume, peso de matéria seca e carbono para diferentes fisionomias da flora nativa. Lavras: UFLA, 2008. cap.3, p.103-114.
Socher, L. G.; Roderjan, C. V.; Galvão, F. Biomassa aérea de uma floresta ombrófila mista aluvial no município de Araucária, PR. Revista Floresta, v.38, n.2, p.245-252, 2008. <http://ojs.c3sl.ufpr.br/ojs/index.php/floresta/article/ viewFile/11619/8154>. 02 Dez. 2013.

SOS Mata Atlântica. Sala de Notícias. <http://www. sosmatatlantica.org.br/index.php?section=press\&action=li stData>. 12 Mar. 2011.

Souza, A. L.; Boina, A.; Soareas, C. P. B.; Vital, B. R.; Gaspar, R. O.; Lana, J. M. Estoque e crescimento em volume, biomassa, carbono e dióxido de carbono em floresta estacional semidecidual. Revista Árvore, v.35, n.6, p.1277-1285, 2011. <http://dx.doi.org/10.1590/S010067622011000700014>.

Souza, A. L.; Boina, A.; Soares, C. P. B.; Vital, B. R.; Gaspar, R. O.; Lana, J. M. Estrutura fitossociológica, estoques de volume, biomassa, carbono e dióxido de carbono em floresta estacional semidecidual. Revista Árvore, v.36, n.1, p.169-179, 2012. $<$ http://dx.doi.org/10.1590/S0100-67622012000100018>.

Sylvestre, L. da S.; Rosa, M. M. T. da. (Orgs.). Manual metodológico para estudos botânicos na Mata Atlântica. Seropédica: Editora UFRRJ, 2002. 123 p.

Tedesco, M. J.; Volkweiss, S. J.; Bohnen, H. Análise de solo, plantas e outros materiais. Porto Alegre: Faculdade de Agronomia, Universidade Federal do Rio Grande do Sul, 1995. 188p. (Boletim técnico de solos, 5).

Urquiza-Haas, T., Dolman, P.M., Peres, C. A. Regional scale variation in forest structure and biomass in the Yucatan Peninsula, Mexico: Effects of forest disturbance. Forest Ecology and Management. v.247, n.1-3, p.80-90, 2007. $<\mathrm{http}: / /$ dx.doi.org/10.1016/j.foreco.2007.04.015>.

Viera, M.; Caldato, S. L.; Rosa, S. F.; Kanieski, M. R.; Araldi, D. B.; Santos, S. R.; Schumacher, M. V. Nutrientes na serapilheira em um fragmento de floresta estacional decidual, Itaara, RS. Ciência Florestal, v.20, n.4, p.611619, 2010. <http://cascavel.ufsm.br/revistas/ojs-2.2.2/ index.php/cienciaflorestal/article/view/2419/1496>. 02. Dez. 2013.

Vitousek, P. M.; Sanford, R. L. Nutrient cycling in moist tropical forest. Annual Review Systems, v.17, p.137-167. 1986. $<$ http://dx.doi.org/10.1146/annurev.es.17.110186.001033>.

Vogel, H. L. M.; Schumacher, M. V.; Truby, P. Biomassa e macronutrientes de uma floresta estacional decidual em Itaara, RS. Revista Árvore, v.37, n.3, p.99-105, 2013. $<$ http://dx.doi.org/10.1590/S0100-67622013000100011>.

Watzlawick, L. F.; Caldeira, M. V. W.; Viera, M.; Schumacher, M. V.; Godinho, T. O. Balbinot, R. Estoque de biomassa e carbono na Floresta Ombrófilo Mista Montana Paraná. Scientia Forestalis, v.40, n.95, p.353-362, 2012. <http:// www.ipef.br/publicacoes/scientia/nr95/cap06.pdf>. 10 Dez. 2013. 